treten, die Studien indirekt fördert, indem sie sie zum Beispiel mit Material oder Geräten unterstützt.

Das wird nicht nur in der Hämatologie zunehmend wichtiger, so Haferlach, wo der Vormarsch der individualisierten Therapie auf der Basis von verbesserter Diagnostik ungebrochen ist.

\section{Diagnostische Methoden bestimmen die Zukunft}

Die Zukunft der diagnostischen Methodik wird durch Geräte bestimmt werden, die das „Next Generation Sequencing“ beherrschen. Damit lassen sich mit bisher nicht gekannter Schnelligkeit und Effizienz molekulargenetische Biomarker, minimale Resterkrankung (MRD) usw. bestimmen und letztlich das gesamte Genom sequenzieren, um anhand dieser Daten die Patienten für individuelle Therapieoptionen zu stratifizieren.

Gerade für Entitäten, die bisher nicht besonders gut charakterisiert waren wie die CLL oder MDS gibt es mittlerweile zahlreiche neue genetische und moleku- lare Marker. So wurde beim ELN-Symposium gezeigt, dass bei der MDS-Diagnostik die Zytogenetik von größerer Bedeutung ist denn je und die nächste Revision des International Prognostic Scoring System (IPSS) bestimmen wird, das in Kürze publiziert werden soll. JosefGulden

Bericht vom $9^{\text {th }}$ Annual Symposium of the European LeukemiaNet, 31. Januar /

1. Februar 2012 in Mannheim

\title{
Next Generation Sequencing
}

\section{Die Zukunft der Diagnostik in der Hämatologie}

Die Hämatologie ist von einer immer stärkeren Individualisierung der Therapie gekennzeichnet. Gab es früher vier Typen von Leukämie, so zerfallen diese heute in Dutzende und aber Dutzende von Subtypen, die unterschiedliche Prognosen haben und teilweise auch unterschiedlich therapiert werden. Ihre Differenzierung erfolgt immer mehr mit molekulargenetischen Methoden, deren Entwicklung in den letzten Jahren geradezu revolutioniert wurde.

\begin{abstract}
T echnische Grundlage dafür ist die Verwendung der neuesten Plattform, nämlich des „Next Generation Sequencing“ (NGS), mit dem sich einzelne Gene, Gen-Panels und in näherer $\mathrm{Zu}$ kunft sogar das gesamte Genom eines Patienten („whole genome sequencing“ oder „whole exom sequencing“) mit einer Schnelligkeit sequenzieren lassen, an die vor wenigen Jahren noch nicht zu denken war, so Prof. Torsten Haferlach, München.
\end{abstract}

\section{Sensitivität gleicht einer PCR}

Gleichzeitig erfolgt die Analyse in einer viel größeren Tiefe als bisher: Bei der klassischen Sequenzierung nach Sanger müssen mindestens $20 \%$ der Zellen eine $\mathrm{Mu}$ tation tragen, um sie detektieren zu können, NGS reduziert das auf $0,1 \%$ - damit wird eine Sensitivität erreicht, wie man sie von der klassischen Polymerasekettenreaktion (PCR) kennt. Damit eignet sich die Technik auch z.B. zur Bestimmung der minimalen Resterkrankung beispielweise bei der CML oder der CLL; allerdings kann man bei NGS pro Ansatz sehr viel mehr Proben verarbeiten als auf herkömmlichen Plattformen.

\section{Sämtliche Mutationen werden abgelesen}

Um die damit erzeugten Datenmengen sinnvoll auswerten und in klinisch brauchbare Befunde zu übersetzen, so Haferlach, ist derzeit noch ein großer Aufwand an Bioinformatik erforderlich; dieser dürfte jedoch in absehbarer Zeit in den Geräten integriert sein. Der wesentliche Unterschied zu den bisherigen molekulargenetischen Methoden ist, dass man nicht mehr spezifische Proben einsetzen muss, die genau auf die gesuchte Mutation zugeschnitten sind, sondern dass einfach das gesamte Gen (oder künftig sogar das gesamte Genom) sequenziert wird und ein Computerprogramm daraus sämtliche vorliegenden Mutationen abliest.

\section{Internationale Forschung bringt Technologie voran}

Die Zuverlässigkeit und Robustheit dieser Technologie, so Dr. Alexander Kohlmann, München, wurde in der IRON-Studie

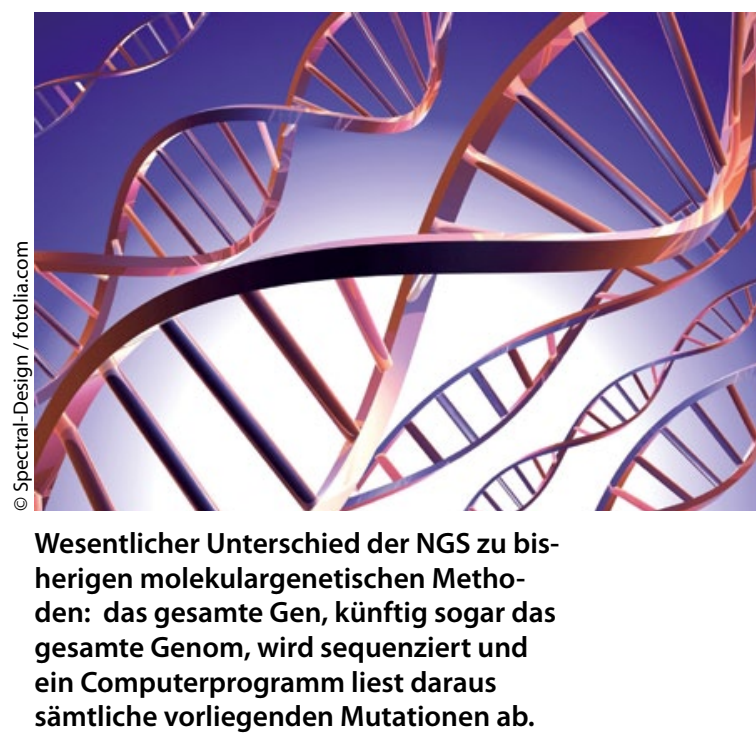

(Interlaboratory RObustness of Next generation sequencing) anhand dreier bei Leukämien häufig betroffener Gene (TET2, CBL, KRAS) von einem internationalen Konsortium in zehn Labors in Europa und Brasilien nachgewiesen [Kohlmann A et al., Leukemia 2011; 25: 1840-8]. In der IRON-II-Studie, die vor Kurzem begonnen hat, wird der Ansatz auf alle Arten von Leukämien, MDS und myeloproliferative Erkrankungen und weitere Gen-Panels ausgeweitet; daran werden etwa 25 Labors in 14 Ländern beteiligt sein.

Josef Gulden
Bericht vom $9^{\text {th }}$ Annual Symposium of the European LeukemiaNet, 31. Januar /

1. Februar 2012 in Mannheim 